\title{
The design of tall structures with particular reference to vibration
}

\author{
R. A. WALLER
}

Mr R. H. Ferahian, Associate Member

Data on the damage potential to structures due to man-made vibrations are scarce. It may be of interest to the readers to refer to some results of research in this field conducted at the Division of Building Research of the National Research Council of Canada. ${ }^{31-34}$ Ref. 34 not only gives data to enable the engineer to estimate the levels of vibrations due to various sources of excitation but also gives a survey of vibration environments (satisfactory and/or unsatisfactory) observed with some vibration sensitive apparatus and equipment. Optimum vibration environments in laboratory buildings are also proposed therein.

76. In $\S 46$ it is stated that damping is in general one order greater as a result of friction at joints, etc.' than that given in Table 1. If reinforced concrete beams are considered, for example, this means that the range and average damping could be 13-62 and $40 \%$ respectively of the critical damping. These values are too high and can only be reached if the vibrations are in the inelastic range. The Author has stated earlier that he is not considering vibrations in the inelastic range. Does he mean therefore that damping can be possibly double that in Table 1 instead of an 'order greater'? Even then this seems to be generally a high value.

77. Damping in the soil in structural dynamics is usually only important in those cases where the rocking mode predominates ${ }^{35}$ (cf. $\$ 48$ ). Table 2 is somewhat misleading, especially for those not experienced in the field of foundation dynamics. Damping due to vibration radiation in the soil is a function of the size, shape, and depth of embedment of the foundation and also the soil properties (material and stratification geometry). The values quoted in Table 2 are therefore applicable only to the special cases treated. Results of model studies are also not directly applicable to real structures and extreme caution must be exercised in applying the results to design.

78. The Paper gives damping its due emphasis and it is hoped that more papers treating this subject will appear in the future. Structural systems that develop increased damping with the increase of vibration amplitude (and/or duration) are of great interest. This is especially important in designing structures for earthquake resistance and also for resistance of abnormally high winds. The Japanese 'slatted shear wall system' is an example developed for earthquake resistance design. Papers on similar solutions will be most useful.

\section{Mr R. A. Waller}

The Author is grateful for Mr Ferahian's comments on the damage potential of vibrations in structures. With regard to the question he raised about $\S 46$ of the Paper, Mr Ferahian has misunderstood the intention, although perhaps the wording could have been clearer. Table 1 gives examples of the damping in structural members including any damping resulting from joints, and gives a range of from $0.5-4 \%$ critical damping which can be compared with the quotation of $0 \cdot 1-1 \%$ for structural materials in the first sentence of $\S 46$. Thus there is a ratio of about 5 between damping in actual structural members and damping which is known to come from the material itself.

80. With regard to Mr Ferahian's comments on Table 2 the intention here was to show by way of example from Whitman and Barkan's work the order of damping

Paper published: Proc. Instn Civ. Engrs, 1971, 48 (Feb.) 303-323. 
that is likely to be present as the result of the interaction between the foundation and the soil. It was never intended that these figures should be taken, without critical examination, for use in design. The overall intention was rather to build up a picture of the sources of vibration damping in a structure and their relative significance.

\section{References}

31. Ferahian R. H. and Hurst W. D. Vibration and possible damage due to the operation of construction machinery. Proceedings of Public Works Congress and Equipment Show, Miami Beach, 1968. National Research Council of Canada, Publication 10706.

32. Ferahian R. H. Vibrations caused by pile driving division of building research. National Research Council Bibliography No. 35, Ottawa.

33. NoRTHWOOD T. D. et al. Blasting vibrations and building damage. Engineer, 1963, 215 (May) 973-978.

34. Ferahian R. H. and WARD H. S. Vibration environment in laboratory buildings. National Research Council of Canada, Publication 11649, October, 1970.

35. Proceedings Summer Symposium Vibrations of soils and foundations Ann Arbor, Michigan, June, 1968. See also RicharT F. et al. Vibrations of soils and foundations. Prentice Hall, New York, 1970. 